\title{
Strategic Methods for Departmental Growth within Higher Education in the U.S. during Tough Economic Times: A Case Study
}

\author{
Neva E. J. Sanders-Dewey *
}

Joy Dudek ${ }^{\dagger}$

\begin{abstract}
The financial welfare of higher education institutions in the United States has long been tied to the country's economic well-being. While the fiscal impact of downturns on higher education is typically reported on a more macro level, the consequences can be felt campus-wide as the effects often trickle down to the departmental level by means of a reduced allocation of funding. As a result, many academic departments are left with the task of proving their institutional worth in order to be allotted the funds necessary for programmatic maintenance. The purpose of this paper is to report on the declining enrollment and shifts in students' academic focus of study across several years at a financially struggling institution, and to outline one department's approach to ensuring programmatic viability through use of strategic methods to garner institutional support by procuring more student majors.
\end{abstract}

Keywords: Higher education, enrollment, budget cuts, academic major

\section{Introduction and Literature Review}

Similar to many other institutions of higher education, the small private college reviewed here has undergone significant, ongoing changes (Hashmi, Saad, \& Madden, 2018) and has been tremendously impacted by several financially debilitating factors over the past several years. Of these issues, a major economic recession and a significant decline in enrollment have been the biggest contributors to the recent fiscal struggles experienced by the institution. As the economic history of the United States suggests, when the labor market becomes financially challenged and the availability of jobs decline, workers often turn to post-secondary education in an effort to obtain a competitive edge in the employment arena (Barr \& Turner, 2013; Dellas \& Koubi, 2003; Douglass, 2010; Worth \& Stephens, 2011). While previous eras of student influx typically benefited more traditional types of higher education establishments (i.e., four-year colleges and universities), more recent data demonstrate that both traditional (i.e., younger, full-time) and non-traditional (i.e., older and part-time) students seeking an undergraduate or advanced degree have begun gravitating towards lower cost schooling alternatives such as community colleges or those offering professional certificates or degrees (Ashburn, Hoover, \& Lipka, 2011; Betts \& McFarland, 1995; Dunbar et al., 2011; Mitchell, 2013). As a result, many traditional types of institutions have not experienced the type of enrollment surge that historically

\footnotetext{
*Ph.D. Chair/Associate Professor of Psychology Canisius College Buffalo, Ny 14120.

Email:sandersn@canisius.edu

†'
} 
helped to ameliorate the financial strain posed by an economic a recession. During this same time frame, many of these same recession-struck institutions have experienced an additional financial blow by the unexpected and unprecedented cuts made to their state and federal funding (Oliff, Palacios, Johnson, \& Leachman, 2013). Although American institutions of higher education have encountered routine economic fluctuations across time, the reverberating effects of the 2008 recession has left some establishments facing financially catastrophic conditions that have resulted in emergent, college-wide reformations, such as programmatic eliminations and unexpected downsizing (Doyle \& Delaney, 2009; Fain, 2009; Glenn, Schmidt, Laster, \& Miller, 2010; Zumeta \& Kinne, 2011).

During the time since the 2008 recession, sustained enrollment difficulties and the associated economic downfall have led to heightened efforts by many higher education institutions to further tighten their budgetary belts (Breneman, 2002; Douglass, 2010; Hoover, 2011; Mitchell, 2013). Charged with the task of addressing both financial conservation and revenue generation issues, those making the upper level financial decisions for these institutions have increasingly focused on the number of students aligned with a department as a key factor in the appropriation of funds, and often provide more liberal allocations for the more societally recognized programs (i.e., flagship programs) and towards the development of new programs to attract new students (Alstete, 2014; Clark \& Bruno-Jofre, 2000; Holley \& Harris, 2010; Kolowich, 2009; Talbert, 2012). Use of this administrative approach, though financially reasonable for an institution as a whole, has had significant functional consequences for many academic departments. Most notably, smaller, less popular departments (i.e., those with fewer student majors) have become less able to compete for the funding necessary to maintain their program or to acquire new students, and middle-sized or non-flagship departments have become burdened by the task of providing proof of their program's institutional worth with little to no funding to support their efforts (Youngblade, 2015).

To make matters increasingly worse at the programmatic level for these departments, an additional threat has been posed by demographic shifts in the workforce (Waseem, Frooghi, \& Khan, 2016) that have led to changes in the demographics of those entering the higher education within the United States. Even with a recession driven increase in non-traditional student enrollment, which has been an influx welcome by financially strapped colleges and universities, the areas of study selected by this type of student population often differs from that of more traditional students. While the traditional student population's interest in time honored degree programs (e.g., history, philosophy) has remained relatively stable, non-traditional students have increasingly made the selection of an academic major based on the relative earning potential tied to a degree (Kimmel, Gaylor, Ray Grubbs, \& Bryan Hayes, 2012; Kohl, 2010). As such, degrees considered to have a better return on investment, such as those in the STEM fields (i.e., Science, Technology, Engineering and Mathematics), have become more alluring to these non-traditional students as careers in these disciplines are typically tied to greater opportunities for immediate employment and higher wages (Koc \& Tsang, 2015; Langdon, McKittrick, Beede, Khan, \& Doms, 2011). The shift in interest towards these areas of study has proven less advantageous for many academic programs (e.g., Humanities, Liberal Arts, Social Sciences) whose degrees have often been associated with limited immediate employment opportu- 
nities and/or require post-graduate education for career advancement (Conn, 2010; National Center for Education Statistics, 2014).

Taken together, these events have contributed to numerous academic departments battling a circular threat: stagnant/declining student numbers that have led to extensive departmental budget cuts and/or a decreased ability to effectively compete for funding, and dwindling funds that have compromised a department's ability to provide the programmatic offerings likely to entice new student majors. As such, the purpose of this paper is to examine the impact of one institution's economic hardships on programmatic functioning across disciplines and to provide evidence for using specifically delineated tactics specifically designed by one department to bolster its institutional support. To best appreciate the reviewed department's decision to develop and utilize the strategies described in this paper, institutional characteristics during the 2001-2016 academic years are provided and details on the progressive unfolding of events that ultimately impacted departmental funding decisions during that time frame are described.

\section{Institutional Characteristics}

During the initial portion of the 2001-2016 time frame, recognized American media sources such as Kiplinger's "Best College Values," Forbes Magazine's list of "Top Private Colleges," and the U.S. News and World Report's "Greatest Colleges and Universities," touted the reviewed institution's academic and student successes. Noted accomplishments included a $96 \%$ average acceptance rate for students applying to medical school and the state's highest pass rates for accounting students taking the CPA exam for the first time. Even though there were large discrepancies in the noted successes and/or the number of student majors housed within the various departments across campus, at that point, the institution had been financially able to unilaterally allot liberal departmental operational budgets. Although a seemingly foreign concept given today's budgetary constraints in many institutions of higher education, departments were not expected to provide detailed proof of expenditures, student success, or departmental size in order to obtain future funding and often ended each academic year with an ample budgetary surplus. In essence, competition for funding was largely obsolete as departments had sufficient allocations for programmatic development and/or maintenance.

A few years into the new millennium and as the reviewed institution began generating less revenue and experiencing a decrease in endowment funding, the business approach to running a private higher education entity gradually emerged. No longer was the era of generally, and often generously, allotted budgets. At that time, the institution directed its pool of resources towards increasing student enrollment through targeted advertising of the more liberally budgeted flagship programs. Although these efforts seemingly led to a rebound with increased enrollment during 2005-2007 (See Figure 1), the upsurge was temporary and the issue of declining enrollment returned with threats to the institution's financial well-being becoming further complicated by the inception of the 2008 recession.

As the institution's economic difficulties continued, administrative efforts turned towards cost control by downsizing personnel and implementing large scale, college-wide budgetary cutbacks. As the financial repercussions of the 2008 recession continued to 
deplete the pool of available resources for budgetary allotments for programs, the concept "return on investment" (ROI) was introduced as a factor in the determination of resource allocation distributions to departments, and funding decisions became increasingly tied to departmental enrollment revenue generation. At that time, some departments responded to the budgetary restrictions with a conservative approach that involved limiting programmatic offerings and rationing allotted funds, while others took a passive "status quo" approach and continued running their program "as is" without making any programmatic or personnel changes. Although it was unknown by faculty members at the time, those making the financial decisions regarding departmental budgeting were increasingly utilizing information on the amount of revenue generated by the number of student majors aligned with a department to construct ROI calculations. As a result, many departments found themselves in an unfortunate circular downfall; stagnant/declining student numbers that left them unable to compete for funding, and dwindling departmental funds that limited the provision of programmatic offerings likely to bolster their number of student majors. As an additional consequence, departments with declining or lower numbers of student majors, which represented less revenue generation, began experiencing additional cuts to their operational budgets and were increasingly denied requests for supplemental funding. It was during that time, and without awareness of the potential for programmatic immobility through use of more conservative or passive tactics, that the faculty members within the department reviewed here collectively opted to make strategic (i.e., non-monetary based) changes to their academic major in an effort to increase their number of student majors and ultimately establish a means by which to obtain the funds necessary to ensure the department's future viability.

\section{Methodology}

\section{Subjects}

Registration and enrollment records for the years 2001-2016 for all undergraduate students attending a small private Jesuit College located in the northeast portion of the United States were extracted from the Registrar's institutional archival data. Included in this data set was information pertaining to the major selected by both incoming and current students and on the enrollment rates for the entire institution during that time frame. Demographic data, including age and gender, were not included in this review.

\section{Procedure}

Raw data on the institution's total enrollment during the 2001-2016 time frame were reported by academic year, and a percent change in enrollment was calculated for both the incoming freshmen and for currently registered students by using the comparative endpoints of 2001 and 2016. The choice of major reported by incoming and by registered students was categorized by year and according to the academic department that housed each major. From this data set, departments with student majors greater than 150 in number for the 2001 academic year, henceforth identified as the biggest or most "popular" 
departmental programs, were selected for inclusion into the review as they were considered equally sized comparison groups. In addition to the sheer number of students affiliated with each department per year, the proportions of the incoming freshmen and of the entire student population choosing each of the nine largest majors were calculated.

\section{Results and Discussion}

Perhaps the most noteworthy occurrence during the time examined in this review was the institution's substantial decrease in total student enrollment with a $-23.4 \%$ change over the 2001-2016 academic years (See Figure 1). Examination of the data on students' selection of academic majors demonstrated a staggering decline in the number of registered, full-time students choosing some of the previously most popular majors (i.e., Biology, Communication, Management, Physical Education, and Political Science; See Table 1) with percent changes of $-23 \%,-51 \%-53 \%,-88 \%$, and $-39 \%$ change respectively (See Table 2 ). Of the nine departments that housed the most popular majors at the beginning of this review's time period, only two (Finance and Psychology) demonstrated a positive change in the number of registered students choosing their program from 2001 to 2016 (i.e., $+46.2 \%$ and $<+1 \%$ change respectively; See Table 2 ).

While the changes to students' selection of these majors are dramatic, these data are greatly impacted by the institution's overall decline in total enrollment (i.e., fewer students equals fewer total majors). As such, data that more accurately represents the shifts in preference that occurred over this time period were obtained by computing the proportion of the total enrollment accounted for by each departmental major (See Table 3 and Figure 2). Results from this method of measurement suggests that the proportion of majors aligned within the Accounting, Biology, and Marketing departments across the 2001-2016 time frame remained relatively unchanged $(+/-1 \%$ change), dropped for the Communication, Management, Physical Education and Political Science departments $(-2.5 \%,-2.6 \%$, $-5.4 \%$ and $-3.7 \%$ change respectively), and increased for the Finance and Psychology departments $(+4.2 \%$ and $+2.3 \%$ change respectively; See Table 3$)$. Interestingly, during that same time frame, the incoming freshmen student groups demonstrated a similar shift in increased interest in the Finance and Psychology majors $(+1.6 \%$ and $+2.6 \%$ change respectively) and decreases for every other major (i.e., Biology, Communication, Management, Marketing, Physical Education and Political Science) except Accounting during that time period (Please see Table 4 for these proportional changes).

Of particular interest was how this data ran counter to the literature regarding both the positive effects of the recession on institutional enrollment rates and the anticipated change in student preference for specific departmental majors during that time period. First, rather than responding to the 2008 recession with an increase in overall total enrollment rates (Barr \& Turner, 2013), data from the reviewed institution indicated a decrease both in the 2008 and 2009 academic years, and enrollment numbers that never again reached the rate that had occurred prior to the recession's onset. Second, these data run counter to the literature reporting anticipated growth in the number of STEM majors (Rothwell, 2013) and decline in the number of individuals seeking a liberal arts degree 
(Jaschik, 2014). Data reflecting the growth in psychology majors during the years 2008, 2009 and 2010 (i.e., 295, 321, and 333 respectively; See Table 1) lend support to the reviewed department's use of the strategies outlined below. Lastly, and used as another point of support for the methods espoused by the department under review, are the data reflecting the increase in interest of incoming students' choice of major for only three departments; Accounting, Finance and Psychology (See Figure 3). These results suggest that use of these strategies may attract more than just current students (i.e., students who change majors while in college) but also those beyond the confines of the institution (i.e., future students).

In summary, the data examined from the institutional records dating 2001-2016 suggest that several noteworthy occurrences have taken place in relation to the reviewed department across time; 1) irrespective of the significant decline in the institution's overall enrollment, the total number of psychology majors has risen, 2) the proportion of incoming students declaring a major in psychology has increased, and 3) the proportion of the entire student population selecting the psychology major has increased. In these regards, the faculty of the reviewed department strongly adheres to the notion that the success of their program and ascent to, and maintenance of, being the largest major on campus is directly tied to the strategies tactically implemented during the past decade. As result of the demonstrated growth and stability, the department has garnered the support necessary for the approval of requests not often granted to other departments making similar demands. Of these authorizations, the most noteworthy include the procurement of four new faculty members, remuneration for conference based travel for faculty and for select students, and full faculty funding for at least ten separate, semester-long sabbaticals. While the strategies implemented involved themes specific to the department's field of study, these no cost methods are discipline malleable and are outlined here for the consideration of use by other departments who may find themselves in transition, in need of an update, or in similar institutional predicaments.

\section{Departmental Strategies Implemented}

During the 2001-2016 time frame, the department under review initiated several tactics intended to increase the number of departmental student majors. These programmatic strategies were developed in manner that would not only glean exposure to the department and the courses offered, but also served to provide a more comprehensive academic experience for the department's student majors. In an attempt to address both endeavors with an empirically supported effort, several concentrated academic minors were created Stache, Perlman, McCann, and McFadden (1994). To ease faculty burden and with attention to resource limitations, these minors were constructed of a combination of classes already offered by the department and by departments serving other academic majors at the reviewed institution. Though psychology centered, these "focused areas of study" included topically related courses from the various other departments including Education, Criminal Justice, Sociology and Biology. Three academic minors (concentrated areas of study) were created to introduce students from other majors with similar interests to the department's offerings and allowed students who were already majors in the department 
the opportunity to add a field specific focus to their studies. The discipline specific areas covered by these minors included Adult Clinical/Counseling, Child Clinical/Counseling, and Child/Family/Community Psychology. The large numbers of students declaring these minors during the time since their inception lend support to the success of this endeavor. As these minors became more popular, so did the demand for the psychology courses comprising these minors which led to an increased need for instructors to teach these courses and, ultimately, administrative support to hire new faculty members within the department. Efforts with this undertaking continue and have resulted in the recent addition of an extremely popular Neuropsychology minor.

Subsequent to the establishment of these academic minors and the resulting student interest stimulated by exposure to these field focused areas in psychology, a senior level practicum/internship course was developed. This three credit course was designed to provide students with a strictly hands-on, experientially based opportunity in the areas represented by the newly developed minors. Although it required some initial legwork, a collaborative, mutually beneficial partnership has been established with various facilities willing to provide these discipline specific learning opportunities to psychology student majors. After receiving approval of their application for enrollment, and in order to obtain course credit, students complete a total of 120 hours of on-site training and direct-contact work (e.g., students working 1:1 with individuals seeking mental health services) that is offered at no cost to the participating agencies. In return, these students are provided an invaluable real-world experience in their chosen field. Often, an additional reciprocal benefit has occurred wherein many participating facilities offer these students, at the culmination of their internship, a part-time or full-time employment position.

Through academic advisement meetings with the increasing number of students who had selected a major and/or minor, it became evident that a crucial area of student development had not yet been directly addressed. While successful in promoting the department to students of other majors and enhancing the departmental majors' awareness of the various fields of psychology via minors and internships, the gap needed to be bridged between these students' developing career interests and their knowledge of how to attain their career aspirations in the field. Due to the fact that many of the students' career goals necessitated an advance degree and that most were unfamiliar with the application process it entails, a "Graduate School Preparatory Seminar" was developed. This tutorial was designed to enhance students' knowledge regarding post matriculation degrees and to facilitate their preparation for the process of applying to post-graduate programs in their chosen field. Included in the seminar were details pertaining to the types of disciplines and degrees available, specific information pertaining to the development of a Curriculum Vita and statement of purpose, and the manner by which to obtain letters of reference in support of their applications. The mass attendance to the initial seminar provided compelling evidence of the need for this endeavor and resulted in the decision to offer annual sessions on the topic. Since the onset of these activities, the department has experienced a verifiable increase in both the number of student majors applying to, and being accepted at, masters and doctoral programs. To date, though data is self-report in nature, up to $70 \%$ of each class of graduating psychology majors have applied to graduate school with an averaged $98 \%$ acceptance rate into these masters and doctoral programs. 
Most recently and an effort to facilitate ease of access to the graduate school seminar information and to utilize a medium popular with the undergraduate population, a departmentally controlled "Youtube" channel and a "wiki" page were created. These web based platforms enabled students to view pre-recorded video versions of the Graduate School Preparatory seminar, watch departmentally funded colloquium, examine student descriptions of completed internship experiences, and obtain samples of student developed vitas and personal statements. In addition, the department developed an online "Psycholopedia" that is updated twice yearly to include detailed information regarding the major, the minors, and the courses being offered in the upcoming semester.

In order to meet the academic needs of students seeking advanced graduate degrees that often require a more scientific rigorous academic background (e.g., M.D., Ph.D.), the department developed a Bachelor of Science degree. This degree program will run as a separate degree from the Bachelor of Arts degree currently offered by the department and involves the requisite completion of several advanced level statistics/research methods courses.

Lastly, and perhaps most enticing to new students, is the development of three separate accelerated programs that will allow students to complete requirements for both a Bachelors and Masters degree thus offering student majors a cost efficient means by which to attain their career objectives in an expedited manner. Of these programs, two are aligned within another department at the undergraduate institution within which the student starts (Psychology BA and Mental Health Counseling MS, and Psychology BA and School Counseling MS), while the other is housed within a partnered local university (Psychology BA and Social Work MSW). For the programs housed within the same institution, students would begin taking graduate level courses during their senior year of their undergraduate education that count both towards the requirements for the Bachelors and for the Masters degrees. For the third program, students will be able to complete the college's core requirements and the courses for the psychology major during their first three years of undergraduate study and then transfer to the partnered program to begin the first of their two years of graduate studies. At present, two applications (one intra-institutional and one inter-institutional) have been submitted to the state's education department and are pending approval before implementation.

On a more micro level, the department under review has also established several opportunities to facilitate interactions between faculty and students majoring or minoring within the program. These practices, which are similar in nature to those espoused by other departmental programs, include, but are not limited to, the following: 1) student selection (rather than randomized assignment) of a specific faculty member for academic advisement, 2) multi-hour, open-door weekly office hours held by faculty, 3) bi-yearly 1:1 student-faculty advisement appointments, 4) opportunities for conducting and/or participating in faculty driven research, 5) the provision of award based stipends for scholarly research activities, and 5) authorship on poster presentations and/or manuscripts on research conducted with faculty members. In addition to these undertakings, students routinely receive mass emails from the department alerting them to opportunities for participation in the various psychology related activities and for information regarding applications for departmentally sponsored clubs and awards. 


\section{Conclusion}

Overall, the purpose of this review is elucidate the impact of significant and continued economic difficulties at one higher education establishment and to discuss the positive implications of one program's development and use of proactive methods to recruit and maintain student majors in an effort to garner institutional support. While the knee jerk reaction to monetary constraints is often to restrict and conserve, the strategic objective utilized by the reviewed department to "do more with less" seemingly paid off. As change is never an easy endeavor to undertake, the resulting success at persevering and, ultimately, thriving during multiple periods of economic difficulties at the reviewed institution has made the collective efforts of the collegial members of the psychology department worthwhile. When compared to the outcome of other social science departments or departments with similar degree characteristics at the institution, which experienced significant student attrition during that time frame and substantial difficulties in securing necessary resources, the modest success obtained by engaging in a preemptive stance was well worth the efforts. While the faculty of the reviewed department recognize the possibility that other factors could be more strongly correlated with the positive trends in student majors (e.g., demographic changes, trends towards the field of psychology), so, too, is the possibility that these outcomes could have been less positive had these methods not been implemented. It is also acknowledged that use of different methods or approaches may have provided more robust results (e.g., high school recruitment, marketing campaigns, program "branding"). These other tactics, however, often involve upfront expenses with no promise of success. The positive outcomes experienced by the reviewed department over the past several years should help to encourage other similar departments to consider the use of at least some of these no-cost, minimally risky methods in the effort to strengthen their program and facilitate longevity at their institution.

Figure 1

Total Undergraduate Enrollment, 2001-2016

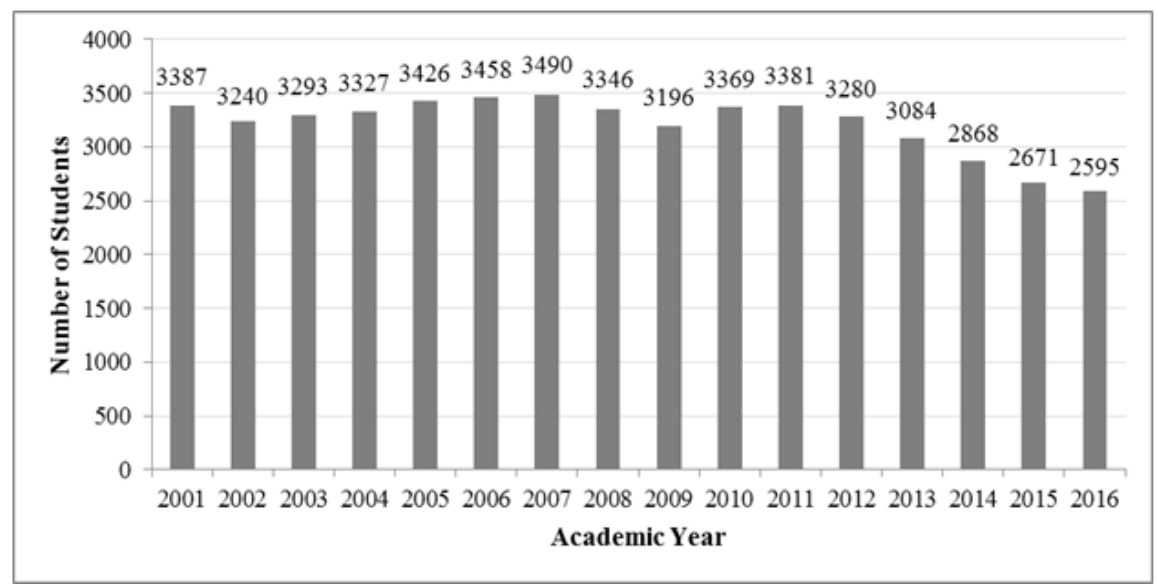




\section{Figure 2}

Proportion of the Entire Student Population Selecting Each of the Nine Reviewed Majors in the Years 2001 and 2016

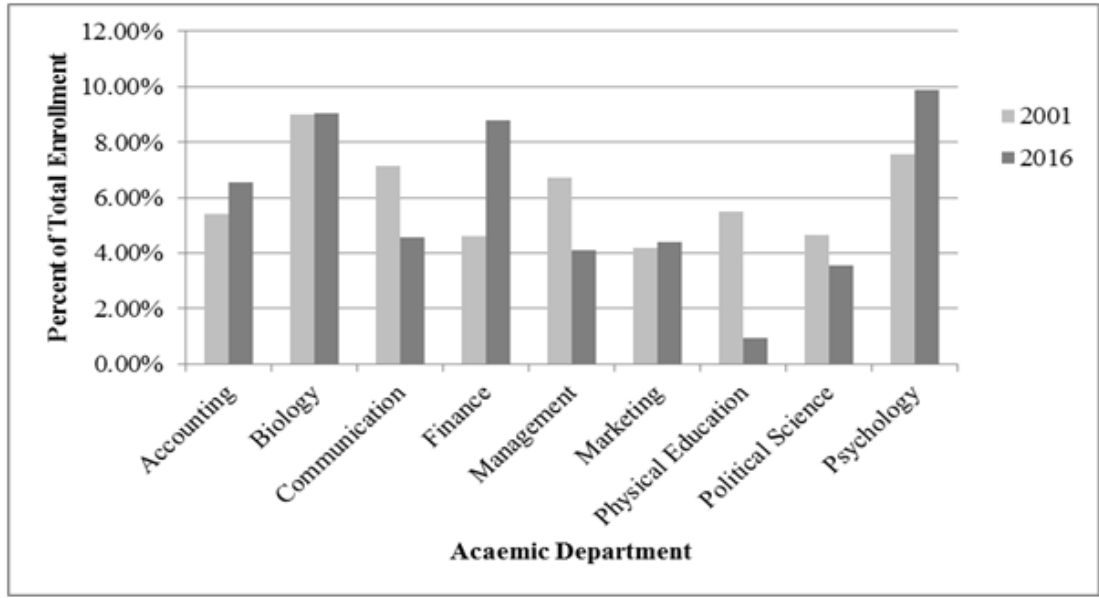

\section{Figure 3}

Proportion of Incoming Students Selecting Each of Nine Reviewed Academic Majors in the Years 2001 and 2016

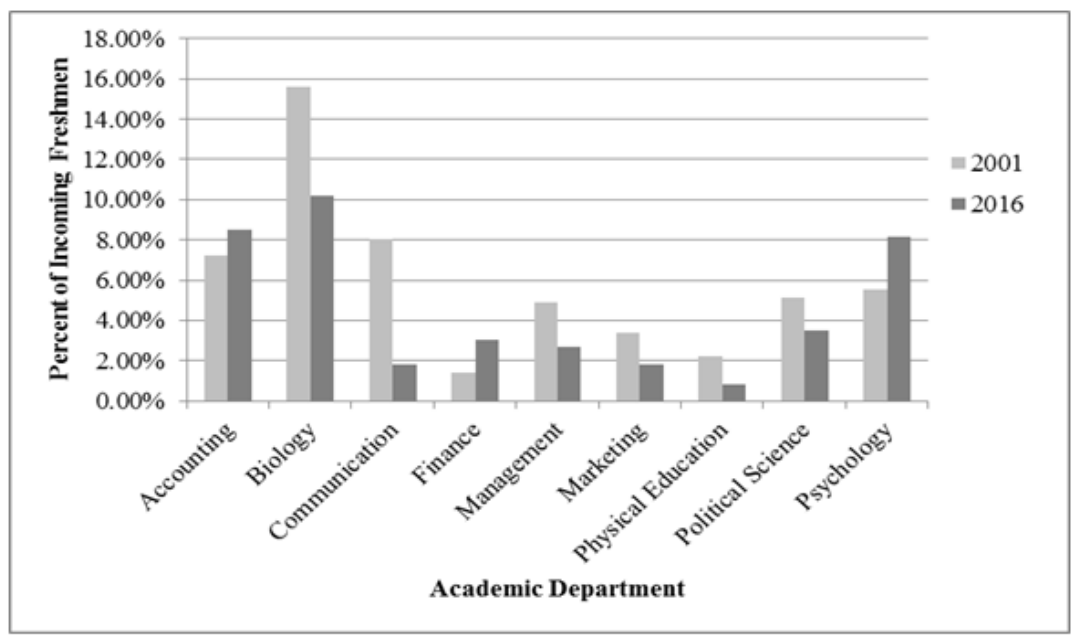


Table 1

Number of Majors Declared in each of the Nine Most Popular Degree Programs, 2001-2016

\begin{tabular}{|c|c|c|c|c|c|c|c|c|c|c|c|c|c|c|c|c|c|}
\hline Academic Major & 01 & '02 & '03 & '04 & 05 & '06 & '07 & 08 & ’09 & 10 & '11 & '12 & '13 & '14 & '15 & '16 & $\mathbf{M}$ \\
\hline Accounting & 184 & 175 & 167 & 205 & 214 & 203 & 206 & 183 & 218 & 229 & 245 & 225 & 223 & 237 & 180 & 170 & 204 \\
\hline Biology & 304 & 233 & 247 & 236 & 260 & 247 & 266 & 266 & 247 & 239 & 275 & 263 & 267 & 249 & 245 & 234 & 254 \\
\hline Communication & 242 & 213 & 208 & 211 & 226 & 215 & 192 & 217 & 212 & 183 & 166 & 139 & 148 & 160 & 140 & 118 & 187 \\
\hline Finance & 156 & 152 & 115 & 95 & 84 & 104 & 119 & 133 & 134 & 143 & 127 & 124 & 156 & 180 & 196 & 228 & 140 \\
\hline Management & 228 & 232 & 218 & 209 & 209 & 189 & 194 & 205 & 173 & 133 & 125 & 125 & 118 & 119 & 111 & 107 & 168 \\
\hline Marketing & 142 & 135 & 156 & 143 & 160 & 170 & 184 & 176 & 170 & 160 & 142 & 152 & 160 & 154 & 145 & 114 & 154 \\
\hline Physical Education & 193 & 171 & 194 & 188 & 187 & 181 & 178 & 170 & 142 & 142 & 114 & 86 & 65 & 50 & 31 & 24 & 132 \\
\hline Political Science & 157 & 126 & 132 & 148 & 132 & 146 & 137 & 108 & 132 & 127 & 102 & 110 & 110 & 107 & 93 & 92 & 122 \\
\hline Psychology & 256 & 259 & 265 & 281 & 293 & 293 & 273 & 295 & 321 & 333 & 294 & 281 & 266 & 272 & 249 & 257 & 281 \\
\hline
\end{tabular}

Table 2

Percent Change in the Number of Majors Declared in each of the Nine Most Popular Degree Programs, 2001 to 2016

\begin{tabular}{lccc}
\hline \multicolumn{1}{c}{ Academic Major } & $\mathbf{0 1}$ & $\mathbf{1 6}$ & $\mathbf{\%}$ Change \\
\hline Accounting & 184 & 170 & $-7.60 \%$ \\
Biology & 304 & 234 & $-23.00 \%$ \\
Communication & 242 & 118 & $-51.20 \%$ \\
Finance & 156 & 228 & $46.20 \%$ \\
Management & 228 & 107 & $-53.10 \%$ \\
Marketing & 142 & 114 & $-19.70 \%$ \\
Physical Education & 193 & 24 & $-87.60 \%$ \\
Political Science & 151 & 92 & $-39.10 \%$ \\
Psychology & 256 & 257 & $<+1 \%$ \\
\hline
\end{tabular}

Table 3

Proportion of the Total Student Population Registered in each of the Nine Most Popular Degree Programs and Percent Change across 2001 to 2016

\begin{tabular}{lccc}
\hline \multicolumn{1}{c}{ Academic Major } & '01 & '16 & \% Change \\
\hline Accounting & $5.40 \%$ & $6.60 \%$ & $1.20 \%$ \\
Biology & $9.00 \%$ & $9.00 \%$ & $0 \%$ \\
Communication & $7.10 \%$ & $4.60 \%$ & $-2.50 \%$ \\
Finance & $4.60 \%$ & $8.80 \%$ & $4.20 \%$ \\
Management & $6.70 \%$ & $4.10 \%$ & $-2.60 \%$ \\
Marketing & $4.20 \%$ & $4.40 \%$ & $0.20 \%$ \\
Physical Education & $5.70 \%$ & $0.30 \%$ & $-5.40 \%$ \\
Political Science & $4.60 \%$ & $0.90 \%$ & $-3.70 \%$ \\
Psychology & $7.60 \%$ & $9.90 \%$ & $2.30 \%$ \\
\hline
\end{tabular}

Table 4

Proportion of Total Incoming Students selecting one of the Top Nine Most Popular Degree Programs and Percent Change across 2001 to 2016

\begin{tabular}{lccc}
\hline \multicolumn{1}{c}{ Academic Major } & $\mathbf{0 1}$ & $\mathbf{1 6}$ & $\mathbf{\%}$ Change \\
\hline Accounting & $7.20 \%$ & $8.50 \%$ & $1.30 \%$ \\
Biology & $15.60 \%$ & $10.20 \%$ & $-5.40 \%$ \\
Communication & $8.10 \%$ & $1.80 \%$ & $-6.30 \%$ \\
Finance & $1.40 \%$ & $3.00 \%$ & $1.60 \%$ \\
Management & $4.90 \%$ & $2.70 \%$ & $-2.20 \%$ \\
Marketing & $3.40 \%$ & $1.80 \%$ & $-1.60 \%$ \\
Physical Education & $2.20 \%$ & $0.80 \%$ & $-1.40 \%$ \\
Political Science & $5.20 \%$ & $3.50 \%$ & $-1.70 \%$ \\
Psychology & $5.60 \%$ & $8.20 \%$ & $2.60 \%$
\end{tabular}




\section{References}

Alstete, J. (2014). Revenue generation strategies: Leveraging higher education resources for increased income. ASHE Higher Education Report, 41(1), 1-138.

Ashburn, E., Hoover, E., \& Lipka, S. (2011). Characteristics haven't changed much, but attitudes have. Chronicle Of Higher Education, 58(1), 30.

Barr, A., \& Turner, S. (2013). Expanding enrollments and contracting state budgets: The effect of the great recession on higher education. The ANNALS of the American Academy of Political and Social Science, 650(1), 168-193.

Betts, J., \& McFarland, L. (1995). Safe port in a storm: The impact of labor market conditions on community college enrollments. Journal of Human Resources, 30(4), 741-765.

Breneman, D. W. (2002). For colleges, this is not just another recession. The Chronicle of Higher Education, 48(40), 7-9.

Clark, B. K., \& Bruno-Jofre, R. D. (2000). Creating entrepreneurial universities: organisational pathways of transformation. The Canadian Journal of Higher Education, 30(2), 171-176.

Conn, P. (2010). We need to acknowledge the realities of employment in the humanities. The Chronicle of Higher Education, 56(30), 6-9.

Dellas, H., \& Koubi, V. (2003). Business cycles and schooling. European Journal of Political Economy, 19(4), 843-859.

Douglass, J. A. (2010). Higher education budgets and the global recession: Tracking varied national responses and their consequences. Research \& Occasional Paper Series: CSHE 4.10.Berkeley, CA: University of California (Tech. Rep.).

Doyle, W. R., \& Delaney, J. A. (2009). Higher education funding: The new normal. Change: The Magazine of Higher Learning, 41(4), 60-62.

Dunbar, A., Hossler, D., Shapiro, D., Chen, J., Martin, S., Torres, V., ... Ziskin, M. (2011). National postsecondary enrollment trends: Before, during, and after the great recession. (signature report 1). Herndon, VA: National Student Clearinghouse Research Center.

Fain, P. (2009). Where dreamers come to die: Florida's public universities face gutted programs and faculty departures. The Chronicle of Higher Education.

Glenn, D., Schmidt, P., Laster, J., \& Miller, M. H. (2010). Disappearing disciplines: Degree programs fight for their lives. The Chronicle of Higher Education, 56(29), 1-11.

Hashmi, K., Saad, I., \& Madden, M. (2018). The emotional politics of educational leaders in higher education institutions: A discursive perspective. Journal of Education $\mathcal{E}$ Social Sciences, 6(1), 40-54.

Holley, K., \& Harris, M. (2010). Selecting students, selecting priorities: How universities manage enrollment during times of economic crises. Journal of College Admission, 207, 16-21.

Hoover, E. (2011). Admissions deans feel crunched by the numbers. Chronicle of Higher Education, 57(36), 1-16.

Jaschik, S. (2014). The STEM enrollment boom. Retrieved from https:// www.insidehighered.com/news/2014/04/07/study-finds-increased -stem-enrollment-recession 
Kimmel, S. B., Gaylor, K. P., Ray Grubbs, M. R., \& Bryan Hayes, J. B. (2012). Good times to hard times: An examination of adult learners' enrollment from 2004-2010. Journal of Behavioral \& Applied Management, 14(1), 18-38.

Koc, E. W., \& Tsang, K. C. (2015). Benchmarking four-year degree completions between the pre- and post-recession periods. National Association of College and Employers (NACE) Journal, 75(4), 15-22.

Kohl, K. J. (2010). Coping with change and fostering innovation: An agenda for professional and continuing education. Continuing Higher Education Review, 74, 9-22.

Kolowich, S. (2009). Recession may drive more adult students to take online classes. Chronicle of Higher Education, 55(19), 11.

Langdon, D., McKittrick, G., Beede, D., Khan, B., \& Doms, M. (2011). STEM: Good jobs now and for the future. ESA Issue Brief\# 03-11. US Department of Commerce.

Mitchell, B. C. (2013). The new rules of engagement. Academe, 99(3), 19-24.

National Center for Education Statistics. (2014). The condition of education. U.S. Department of Education: Washington, DC. Retrieved from http://nces.ed.gov/ programs/coe/indicator.cbc.asp

Oliff, P., Palacios, V., Johnson, I., \& Leachman, M. (2013). Recent deep state higher education cuts may harm students and the economy for years to come. Center on Budget and Policy Priorities, 1-21.

Rothwell, J. (2013). The hidden STEM economy. Metropolitan Policy Program at Brookings Washington, DC: Brookings.

Stache, C., Perlman, B., McCann, L., \& McFadden, S. (1994). A national survey of the academic minor and psychology. Teaching of Psychology, 21(2), 69-74.

Talbert, P. Y. (2012). Strategies to increase enrollment, retention, and graduation rates. Journal of Developmental Education, 36(1), 22-36.

Waseem, S. N., Frooghi, R., \& Khan, B. S. (2016). Empirical assessment of the constructs: Workplace engagement, job burnout and turnover intention. Journal of Education $\mathcal{E}$ Social Sciences, 4(2), 112-131.

Worth, J., \& Stephens, C. J. (2011). Adult students: Meeting the challenge of a growing student population. Association of American Colleges and Universities, 13(1), 23-25.

Youngblade, L. (2015). Strategic planning: View from the departmental level. Academic leadership in higher education: From the top down and the bottom up, 251-258.

Zumeta, W., \& Kinne, A. (2011). The recession is not over for higher education. In the NEA 2011 almanac of higher education. Washington, DC: National Education Association. 